$\xi=-1$

\title{
Effect of Particle Size and its Distribution on Rheological Behaviour of Coal-Water Slurry
}

\author{
Ganeswar Sahoo $^{1 *}$, Anupama Routray ${ }^{2}$, Mamata Kumari Padhy $^{2}$, P.K. Senapati ${ }^{3}$ \\ ${ }^{1}$ KIIT University, Bhubaneswar-751024 \\ ${ }^{2}$ Siksha 'O' Anusandhan University, Bhubaneswar-751030 \\ ${ }^{3}$ CSIR-IMMT, Bhubaneswar-751013 \\ *Corresponding author E-mail:ganeshproff@gmail.com
}

\begin{abstract}
An experimental investigation has been conducted to study the rheological behaviour of coal-water slurry (CWS) of low rank coal. Different samples have been prepared by pulverizing it to powder form. Bi-modal and mono-modal samples have been prepared separately. Thereafter slurry was prepared by adding distilled water to the sample. CWS of different coal concentration have been prepared with particle size from $37 \mu \mathrm{m}$ to $250 \mu \mathrm{m}$. The rheological behaviour of both mono-modal and bi-modal slurry have been investigated with help of HAAKE RHEO STRESS 1, a thermo scientific rheometer. Comparing the rheological behaviour of CWS prepared from bi-modal sample and mono-modal sample, it is observed that CWS from bimodal exhibit lower viscosity and shear stress compare to mono-modal sample. The stability of slurry prepared from bi-modal samples are found to be poor than mono-modal samples. The stability of coal sample below $75 \mu \mathrm{m}$ at different concentration has also been investigated. Also the characterization of coal sample has been done. It is observed that as the ratio of coarse particle decreases the shear stress and viscosity also decreases.
\end{abstract}

Keywords: Coal-Water slurry, Particle size distribution, Rheology, Stability

\section{Introduction}

Coal-water mixture is a viscous fluid having viscosity similar to crude oil which can replace the fuel oil used in oil fired boiler [1]. Earlier coal-oil mixture was used as fuel in oil fired boiler. Gradually large emphasis is given on coal-water fuels due to its good liquidity, stability, non-flammable and non-polluting properties [2]. The coal water slurry (CWS) is generally utilized in gasification of coal [3] and used as the fuel source in boiler combustion [4]. Generally coal-water slurry is the mixture of $60-75 \%$ solid particles, $35-40 \%$ water and about $1 \%$ additives (optional) [5, 6]. While preparing coal-water slurry, coal concentration is kept high, keeping the viscosity lower to get higher heating value, easy handling during preparation and transportation [7] and economical pumping power [8]. Less viscous slurry affects the rheological behaviour and wall-slip behaviour over wide range of wall shear stress [9]. This paper explains the findings of the experimental investigation of the rheological behaviour of CWS of mono-modal and bi-modal coal sample. Also it explains the investigation results of the static stability of the slurry.

\section{Experimental}

\subsection{Materials}

The coal samples were collected from the Mahanadi coal field limited (MCL), Odisha, India. They were crushed and sieved into different smaller particle sizes. The different sizes considered for experimentation are as follows: $-250 \mu \mathrm{m},-210 \mu \mathrm{m},-150 \mu \mathrm{m},-105$ $\mu \mathrm{m},-75 \mu \mathrm{m}$ and $-37 \mu \mathrm{m}$. The proximate and ultimate analyses of coal sample are shown in Table 1.
CWS consisting of different composition of mono-modal and bimodal samples considered for study of the rheological behaviour are as follows: $-37 \mu \mathrm{m},-75 \mu \mathrm{m},(-105 \mu \mathrm{m}+75 \mu \mathrm{m}),(-210 \mu \mathrm{m}+$ $105 \mu \mathrm{m})$ and $(-250 \mu \mathrm{m}+150 \mu)$. The bi-modal sample were prepared by mixing coarse particles with fine particle with different proportions like coarse to fine ratio is 0.8:0.2, 0.7:0.3 and 0.6:0.4. The coarse particles size distribution were considered as $(-105 \mu \mathrm{m}$ $+75 \mu \mathrm{m}),(-210 \mu \mathrm{m}+105 \mu \mathrm{m})$ and $(-250 \mu \mathrm{m}+150 \mu \mathrm{m})$ and the fine particles were taken as $-37 \mu \mathrm{m}$. The characterization of coal sample was carried out.

\subsection{Ph Value Measurement of the Sample}

Coal particles release either $\mathrm{H}^{+}$or $\mathrm{OH}^{-}$ions when mixed in water, depending upon the $\mathrm{pH}$ medium. They undergo hydration, hydroxylation, and finally acquire this surface charge. Hence a fresh slurry sample was prepared by mixing 50\% distil water and 50\% coal particle (by vol.) and placed in a $150 \mathrm{ml}$ beaker. A thermo scientific ORION STAR A211 pH meter was used to measure the $\mathrm{pH}$ of slurry. The test was conducted at room temperature. The electrode of the $\mathrm{pH}$ meter was doped in the slurry for 5 hours and steered continuously. The $\mathrm{pH}$ value of the slurry was recorded in every half an hour. After 5 hours the $\mathrm{pH}$ of the slurry was found to be stable and considered as the final $\mathrm{pH}$ of the coal water slurry.

\subsection{Density Test}

BOROSILICATE density glass pot of $50 \mathrm{ml}$ size was chosen for the density test. The tests were carried in three density glass pot for better and accurate result and finally its average value was calculated. Initially the weight of the empty bottle (A) was record- 
ed. Then weight of the bottle with sample ( $40 \%$ by volume of the pot) (B) and weight of the bottle with sample filled with enough water (C) were noted down. The weight of the bottle filled with distil water (D) was also noted down. Then the particle density was calculated as follows.

$$
\text { Particle density }=\frac{(B-A)}{(D-A)-(C-B)} \mathrm{gm} / \mathrm{cc}
$$

\subsection{Determination of Maximum Static Settled Concen- tration $\left(\mathrm{C}_{\mathrm{w}} \mathrm{Max} \%\right)$}

$\mathrm{C}_{\mathrm{w}}$ max percentage of slurry gives the result of maximum solid concentration that can be absorbed by the slurry, where slurry exhibits its Newtonian behaviour. To conduct the test the coal particles with different concentration i.e. $45 \%, 50 \%, 55 \%, 60 \%$ and $65 \%$ by weight were taken in different jars. Remaining percentage of distil water is added to the solid concentration by volume. For better and accurate result two samples were prepared for each concentration. At initial stage due to the non-Newtonian behaviour $65 \%$ concentration was not considered for the test. The sample initial reading were noted down and left for settle down for $48 \mathrm{hrs}$.

\subsection{Particle Size Analysis}

Particle size analysis was done to find out percentage of particles with the different particle size present in a sample. This gives the result of particle size distribution by volume. PARTICA LA-960 a particle size analyser of HORIBA SCIENTIFIC was used as shown in Fig. 2.1. The total system is a complete arrangement of particle size analyser, compressor, an arrangement of sample suction, and a computer. The test was conducted by both dry and wet method. $20 \mathrm{gm}$ coal sample of $-75 \mu \mathrm{m}$ was taken and dried for half an hour to remove the moisture. 10 to 15 gm of dry sample was poured in the cup of particle size analyser and passed through the laser scattering. The results were generated based on incident ray and reflected ray and displayed in the computer screen. After the test the wastage portion of the samples were sucked by the vacuum sucker and drained.

\subsection{Rheology Test}

HAAKE RHEO STRESS 1, a thermo scientific rheometer was used to study the rheological behaviour of coal-water slurry. The total arrangement consisted of rheometer, chiller, compressor, computer and a printer as shown in Fig. 2.2. The chiller is used to maintain the temperature of sample cup used in rheometer. One rotor was attached to the spindle which mainly calculated the shear stress, shear rate and viscosity. Different rotors are used for coarse and fine particle i.e. for fine Z41 and for coarse particle $\mathrm{Z} 38$ rotor were used. The rotor and the cup distance were set to zero. $30 \mathrm{ml}$ of slurry sample was poured in the preheated cup and placed in the rheometer. The rotor was fitted to the spindle and test was conducted.

Sample rheology data were collected and noted down. The rotor was detached from the spindle and rotor cup was taken away for cleaning. For each sample the experiment was repeated twice and average values of output data were considered for further analysis. The results were fitted with non-Newtonian fluid flow model, i.e.

Power Law or Ostwald de Waele model, $\tau=\mathrm{k} \gamma^{\mathrm{n}}$

And Bingham plastic model, $\tau=\tau_{0}+n_{\mathrm{p}} \gamma$

Where $\tau=$ Shear stress $\quad \gamma=$ Shear rate

$\tau_{0}=$ Yield stress $\quad \mathrm{k}=$ Flow consistency index

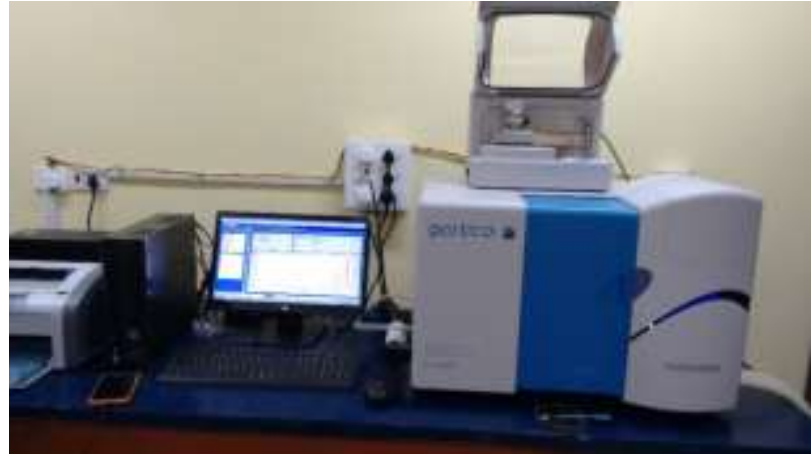

Fig. 2.1: Particle size analysis with PARTICA LA-960

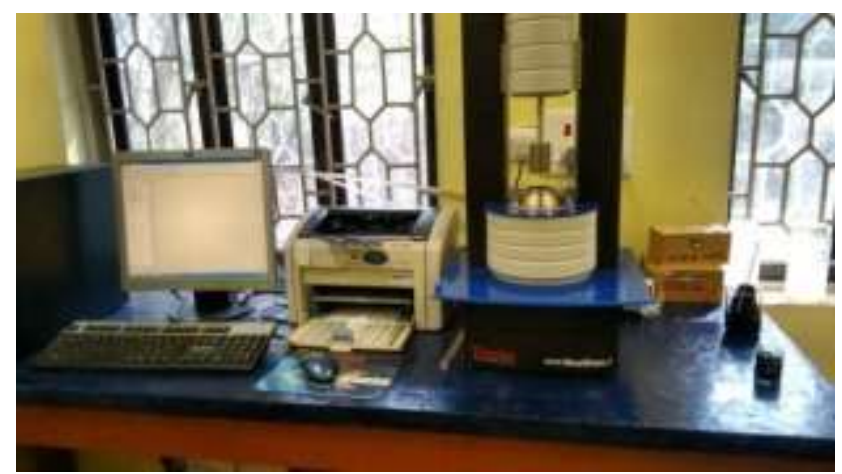

Fig. 2.2: Rheology test of CWS with HAAKE RHEO STRESS 1

\subsection{Static Stability Test}

The samples of coal-water slurry were prepared with different concentrations i.e. $\mathrm{C}_{\mathrm{W}}=60 \%, 57.5 \%, 55 \%$ and $52.5 \%$ as presented in Table 2. Sample coal-water slurry is shown in Fig.2.3. The slurry was placed in four $100 \mathrm{ml}$ beaker covered with aluminium foil and left for settling down. Stability test was conducted by rod penetration method. A glass rod of $19 \mathrm{~g}$ with $5 \mathrm{~mm}$ diameter was used for the test. In every 24 hours interval the rod was penetrated inside the slurry and the effective travel distance was noted down. The penetration ratio was calculated as follows.

Penetration ratio $(\%)=\frac{d}{d_{t}} \times 100$

Where $\mathrm{d}=$ Effective travel distance $($ in $\mathrm{cm}$ ) by glass rod $\mathrm{d}_{\mathrm{t}}=$ Maximum travel distance (in $\mathrm{cm}$ ) by glass rod

\section{Results and Discussion}

\subsection{Measurement of $\mathrm{pH}$}

The $\mathrm{pH}$ values of CWS were noted down in every half an hour interval. After 5 hours $\mathrm{pH}$ value is found to be stable and considered as the final reading. Finally the $\mathrm{pH}$ value was found to be 7.040. It was found to be within range of 6 to 8 which was a good result to proceed further.

\subsection{Density Test}

For the accurate result three sets of test were conducted. Final reading is calculated by taking the average. The density is found to be $1.689 \mathrm{gm} / \mathrm{cc}$. 
Table 1

Proximate analysis of coal sample dry basis:

\begin{tabular}{|c|c|c|c|c|}
\hline Inherent Moisture (\%) & & Ash $(\%)$ & Volatile matter $(\%)$ & Fixed Carbon $(\%)$ \\
\hline 5.76 & & 37.89 & 24.22 & 32.13 \\
\hline \multicolumn{5}{|c|}{ Ultimate analysis of coal sample dry basis: } \\
\hline $\mathrm{C}(\%)$ & $\mathrm{H}(\%)$ & $\mathrm{N}(\%)$ & $\mathrm{O}(\%)$ & $\mathrm{S}(\%)$ \\
\hline 84.26 & 4.72 & 1.75 & 8.66 & 0.5 \\
\hline
\end{tabular}

Table 2

\begin{tabular}{llc}
\hline Particle size & weigh of coal in $(\mathrm{g})$ & Water in ml \\
\hline$-75 \mu \mathrm{m}$ & 60 & 40 \\
$-75 \mu \mathrm{m}$ & 57.5 & 42.5 \\
$-75 \mu \mathrm{m}$ & 55 & 45 \\
$-75 \mu \mathrm{m}$ & 52.5 & 47.5
\end{tabular}

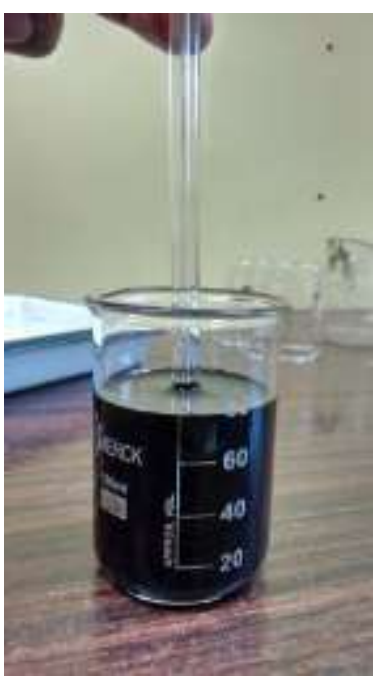

Fig. 2.3:. Stability test with rod penetration

\subsection{Maximum Static Settled Concentration $\left(C_{\mathrm{w}} \operatorname{Max} \%\right)$}

The $\mathrm{C}_{\mathrm{w}}$ maximum percentage was found to be $61 \%$. At $65 \%$ concentration, the slurry became thicker and the test could not be carried out.

\subsection{Particle Size Distribution Analysis}

The particle size distribution test was conducted with $-75 \mu \mathrm{m}$ size MCL coal. By considering the major percentage of particle size, a graph was plotted between on a semi log sheet between particle diameter $(\mu \mathrm{m})$ and undersize (\%) as shown in Fig. 3.1.

The mean particle size was found to be $26 \mu \mathrm{m}$ with $69.6 \%$ undersize and 2.9 volume percentage. The median size $\left(\mathrm{d}_{50}\right)$ was observed to be $14 \mu \mathrm{m}$ with having 7.4 volume percentage and $47.9 \%$ undersize.

\subsection{Stability Test}

The stability test was carried to determine the settling rate of the slurry. The stability test of bi-modal slurry was done. But due to poor stability the data were not recorded. Again the stability test of

particle size $-75 \mu \mathrm{m}$ was done and the data were recorded. From the Fig 3.2 it was found that the stability of CWS with $C_{w}=60 \%$ was much better than the other concentration. The penetration ratio of slurry with $\mathrm{C}_{\mathrm{w}}=60 \%$ was found to be $93.61 \%$ and lasts up

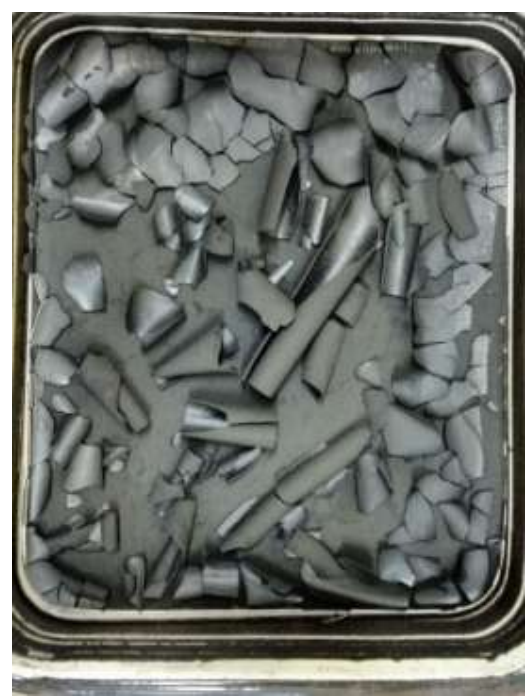

Fig. 2.4: Particles below $37 \mu \mathrm{m}$

to 11 days. Whereas at $\mathrm{C}_{\mathrm{w}}=52.5 \%$ the penetration ratio was found to be $85 \%$ and lasts up to 11 days.

\subsection{Study of rheological behaviour}

\subsubsection{Slurry of Mono-Modal Sample}

Initially the rheology of the mono-modal coal sample was carried out. The particle size below $75 \mu \mathrm{m}$ was selected with four different concentration i.e. $\mathrm{C}_{\mathrm{w}}=60 \%, 57.5 \%, 55 \%$ and $52.5 \% . \mathrm{C}_{\mathrm{w}}=60 \%$, that means $60 \mathrm{~g}$ coal and $40 \mathrm{ml}$ water. Likewise other proportions were taken. In rheology basically viscosity and shear stress were measured with respect to shear rate. After generating the data graphs were plotted as follows.

From the Fig. 3.3 it is observed that as the coal-water slurry concentration increases, the shear stress of the slurry also increases. At $\mathrm{C}_{\mathrm{w}}=52.5$ the shear stress is observed to be minimum 2.77 $\mathrm{Pa}$ at $10.81 \mathrm{~s}^{-1}$ shear rate and it gradually increases as the concentration increases. At highest concentration of $\mathrm{C}_{\mathrm{w}}=60$, the shear stress was observed to be $13.35 \mathrm{~Pa}$. At the same time in Fig 3.4 viscosity was also observed to be increasing as the concentration of slurry increased. At $\mathrm{C}_{\mathrm{w}}=52.5$ viscosity was observed to be minimum of $0.256 \mathrm{~Pa}$.s at $10.81 \mathrm{~s}^{-1}$ shear rate. The maximum shear stress was observed to be $1.379 \mathrm{~Pa} . \mathrm{s}$ at shear rate of $9.687 \mathrm{~s}^{-1}$ during the initial point of $\mathrm{C}_{\mathrm{w}}=60$. 


\subsubsection{Slurry of Bi-Modal Sample}

For the first sample coarse particle was taken as $(-210+105) \mu \mathrm{m}$ and fine particle was taken $-37 \mu \mathrm{m}$ (as shown in Fig. 2.4). The slurry was prepared with different proportion like 0.8:0.2, 0.7:0.3 and 0.6:0.4. From the Fig. 3.5 it is observed that as the coarser content increases in sample the slurry shear stress also increases. The shear stress is found minimum of $1.147 \mathrm{~Pa}$ at shear rate 10.84 $\mathrm{s}^{-1}$ with the proportion of $6: 4$. At proportion of $8: 2$ the shear stress was found to be $2.816 \mathrm{~Pa}$ at shear rate of $11.0 \mathrm{~s}^{-1}$ during the initial stage. Likewise in Fig. 3.6 viscosity was observed to be increasing as the finer content reduced. Viscosity was found minimum 0.106 Pa.s with proportion of $6: 4$ at 10.84 shear rate $\mathrm{s}^{-1}$. At 8:2 proportion it was observed to be $0.256 \mathrm{~Pa}$.s at $11.0 \mathrm{~s}^{-1}$ shear rate. From Fig 3.7 it was found that as shear stress coarse particle content increases, shear rate also increase.

Similarly in next set of sample the coarse particle size was selected as $(-250+150) \mu \mathrm{m}$ and for fine size particles $-37 \mu \mathrm{m}$ was selected. Again the slurry was prepared with three different proportion i.e. 8:2, 7:3 and 6:4 and the rheology behaviour was studied at $\mathrm{C}_{\mathrm{w}}=57.5 \%$. From the above Fig 3.5 it can observe that increased in coarser particles in the sample, shear stress of the slurry increases. The shear stress was found to be minimum of $0.618 \mathrm{~Pa}$ at shear rate of $10.83 \mathrm{~s}^{-1}$ for sample type 6:4. Again at proportion 8:2 the shear stress was observed to be $2.33 \mathrm{~Pa}$ at shear rate $10.49 \mathrm{~s}^{-1}$ during the initial stage. Similarly the apparent viscosity is observed to be decreasing as the ratio of fine particles increases. From the Fig 3.8 the apparent viscosity is found to be minimum $0.057 \mathrm{~Pa}$.s with the proportion of coarser to fine $6: 4$ at shear rate $10.83 \mathrm{~s}^{-1}$. At proportion 8:2 the apparent viscosity is observed to be 0.222 Pa.s at shear rate $10.49 \mathrm{~s}^{-1}$. From all the graphs it is observed that apparent viscosity decreases with increase in shear rate. It allows the slurry to behave as flow able liquid. Also from the above set of experiments it is observed that as finer content increases apparent viscosity and shear stress of the slurry decreases. From the above interpretation it can be predicted that the extreme fine particles in a bi-modal suspension behave as fluid towards the coarse particles.

\subsubsection{Comparison between Slurry of Mono-Modal and Bi-} Modal Sample

After a few sets of experiment, few comparisons were found between bi-modal and mono-modal slurry by taking its rheological behaviour. From the Fig 3.9 and Fig 3.10, it can be observed that slurry prepared from bi-modal sample have comparatively less shear stress and viscosity in comparison to slurry prepared from mono-modal sample. It was also found that slurry prepared from particle size $(-75+105) \mu \mathrm{m}+(-37 \mu \mathrm{m})$ exhibit comparatively higher apparent viscosity among the other bi-modal slurry. $(-250+150)$ $\mu \mathrm{m}+(-37 \mu \mathrm{m})$ exhibit lowest shear stress and apparent viscosity compare to $(-75+105) \mu \mathrm{m}+(-37 \mu \mathrm{m})$ slurry prepared from bimodal sample. With the particle size $(-250+150) \mu \mathrm{m}+(-37 \mu \mathrm{m})$, initially the shear stress and apparent viscosity was found to be $0.618 \mathrm{~Pa}$ and $0.057 \mathrm{~Pa}$.s respectively at a shear rate of $10.83 \mathrm{~s}^{-1}$. Where as in case of slurry prepared from particle size $-75 \mu \mathrm{m}$ showed shear stress and viscosity $10.7 \mathrm{~Pa}$ and $0.969 \mathrm{~Pa}$.s respectively at a constant shear rate of $10.7 \mathrm{~s}^{-1}$. From the study of rheological behaviour, it was found to satisfy both Binghum model and Ostwald De Waele model.

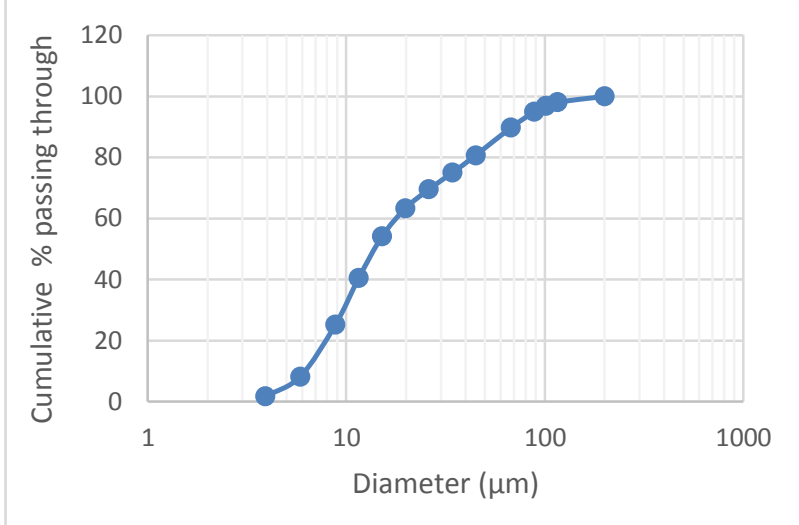

Fig. 3.1: Result of particle size distribution.

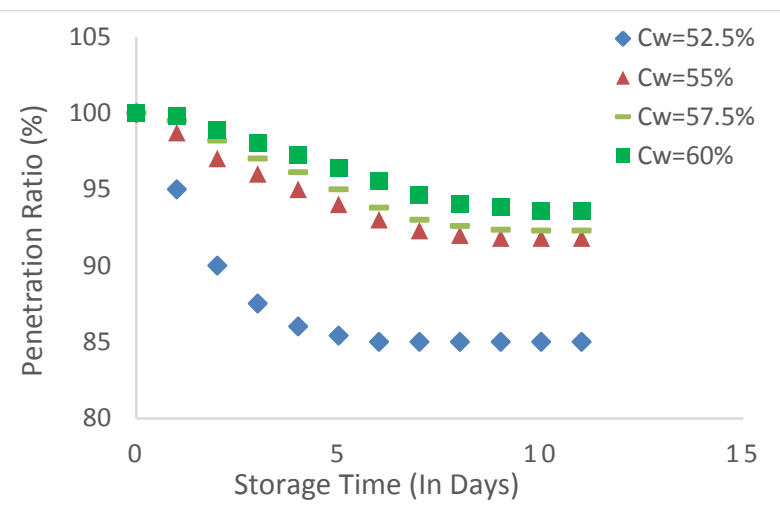

Fig. 3.2: Stability test of $-75 \mu \mathrm{m}$ coal water slurry at different concentration.

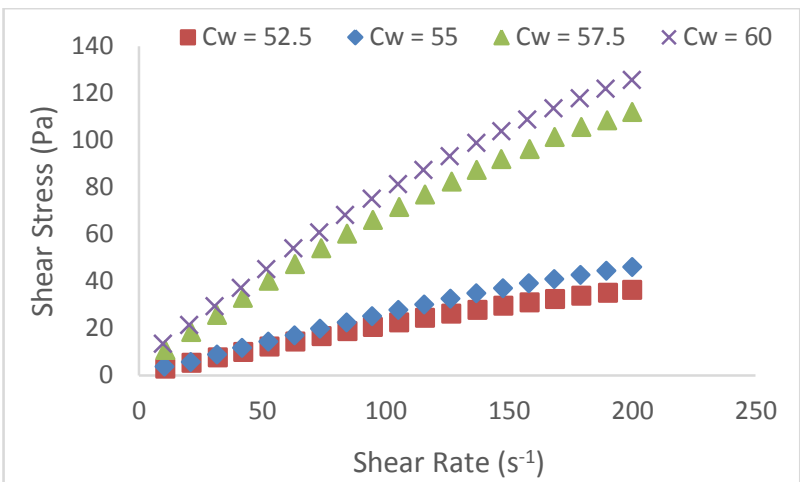

Fig. 3.3: Slurry prepared from mono-modal sample at different concentration

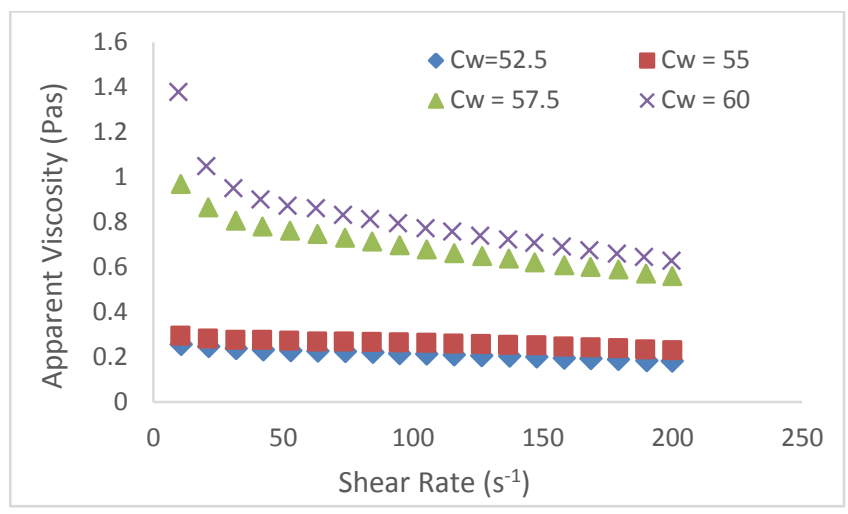

Fig. 3.4: Slurry prepared from mono-modal sample at different concentration 


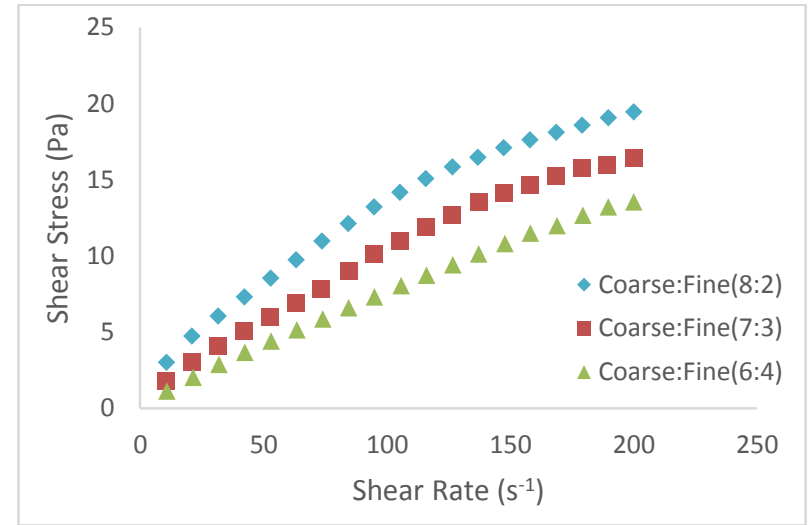

Fig. 3.5: Slurry at $\mathrm{C}_{\mathrm{w}}=57.5 \%$, the particle size $(-210+105) \mu \mathrm{m}+(-37 \mu \mathrm{m})$

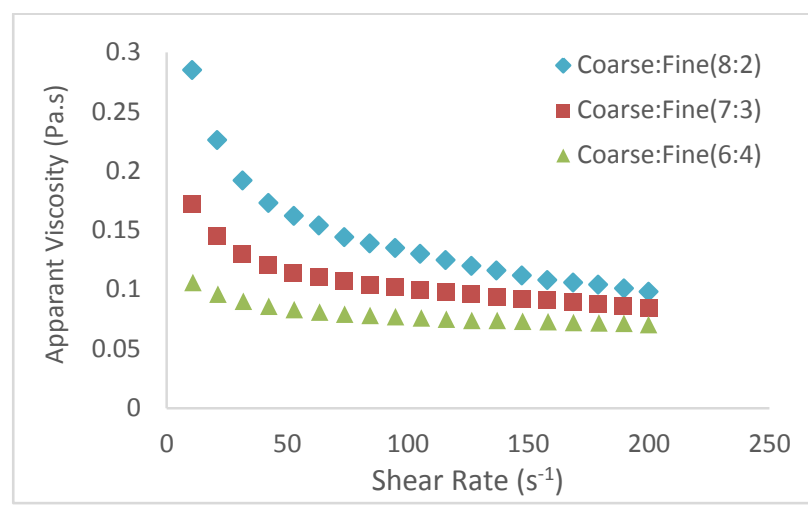

Fig. 3.6:. Slurry at $C_{w}=57.5$, the particle size $(-210+105) \mu \mathrm{m}+(-37 \mu \mathrm{m})$

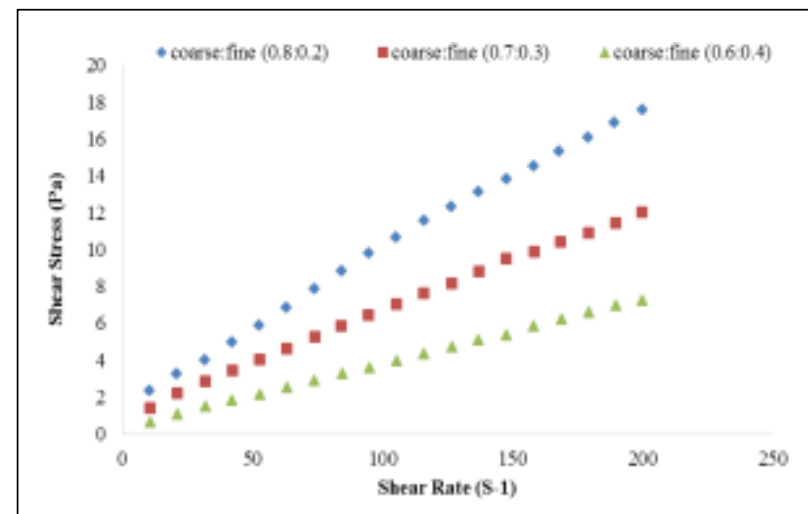

Fig. 3.7: Slurry at $C_{w}=57.5$, the particle size $(-210+105) \mu \mathrm{m}+(-37 \mu \mathrm{m})$

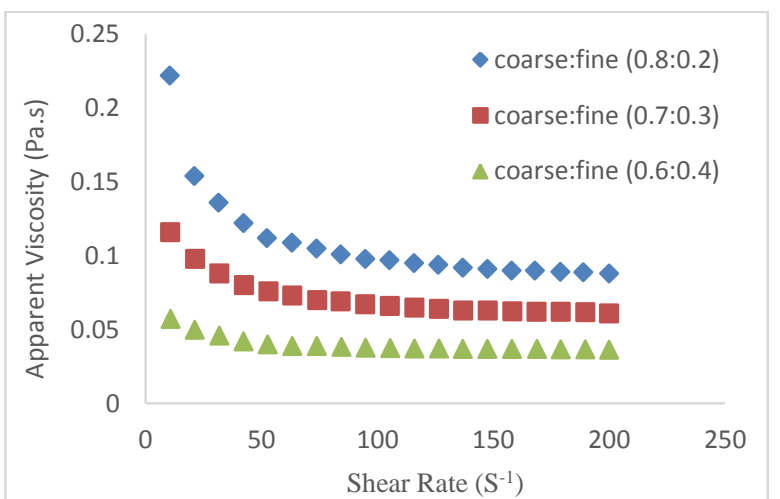

Fig. 3.8: Slurry at $C_{w}=57.5 \%$, the particle size $(-250+150) \mu \mathrm{m}+(-37 \mu \mathrm{m})$

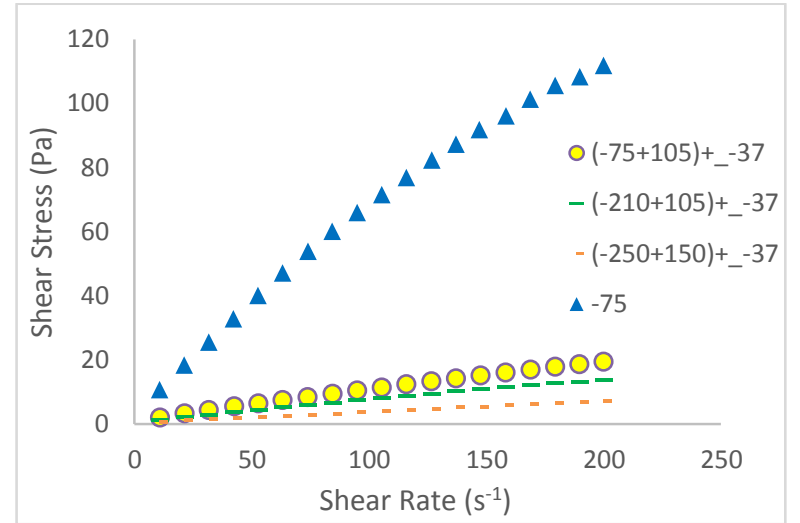

Fig. 3.9: Comparison of shear stress between bi-modal and mono-modal slurry at $\mathrm{C}_{\mathrm{w}}=57.5 \%$.

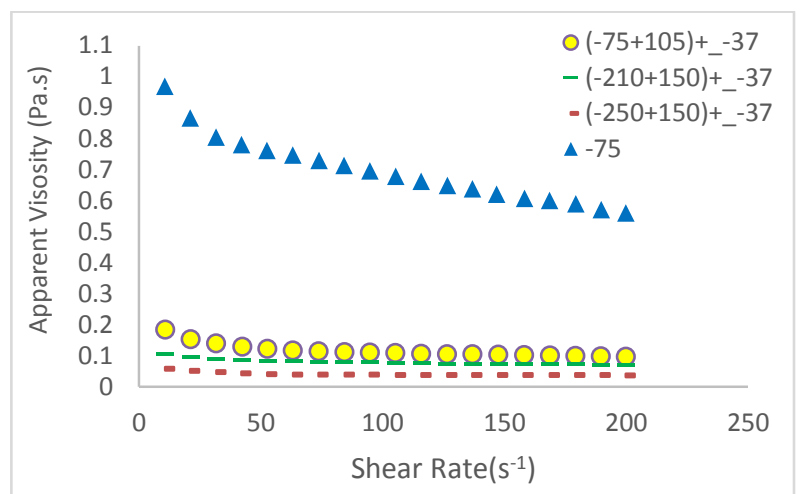

Fig.3.10:.Comparison of apparent viscosity between bi-modal and monomodal slurry at $\mathrm{C}_{\mathrm{w}}=57.5 \%$.

\section{Conclusions}

From the present experimental study it was observed that shear stress increases with increase in shear rate. The viscosity of CWS was observed to be decreasing with increase in shear rate. The slurry prepared from bi-modal sample showed lower viscosity and shear stress with respect to shear rate comparing with CWS prepared from mono-modal sample. From different categories of bimodal sample like $(-105+75) \mu \mathrm{m}+(-37 \mu \mathrm{m}),(-210+105) \mu \mathrm{m}+(-$ $37 \mu \mathrm{m})$ and $(-250+150) \mu \mathrm{m}+(-37 \mu \mathrm{m})$, CWS prepared from ($105+75) \mu \mathrm{m}+(-37 \mu \mathrm{m})$ showed lowest shear stress and viscosity compared to others.

Along with this the stability of CWS was studied from monomodal and bi-modal sample. It was observed that the slurry prepared from bi-modal sample with different proportion exhibit poor stability. The slurry prepared from mono-modal sample exhibit a better stability with higher concentration of coal at $\mathrm{C}_{\mathrm{w}}=60 \%$. Lower the concentration was observed comparatively poor stability.

\section{Acknowledgements}

The author thanks the Institute of Minerals and Materials Technology-CSIR, Bhubaneswar, India for providing laboratory facilities to carry out this part of the research.

\section{Referencess}

[1]. Atesok, G., Boylu, F., Stirkeci, A. A., Dincer, H., The effect of coal properties on viscosity of coal-water slurries, Fuel 2002; 81:18551858.

[2]. Kubica R., Smó k a W., 2000 - Zawiesinowepaliwawêglowe, rozwój, charakterystykaiperspektywyzastosowania. Gospodarkapaliwamii energi ${ }^{1} 2,1$.

[3]. Yun Zengjie, Wu Guoguang, MengXianliang, Zhang Yuliang, Shi Frank, He Yaqun, LuoXiaoqiang, A comparative investigation of 
the properties of coal-water slurries prepared from Australia and Shenhua coals, Mining Science and Technology (China) 21 (2011) 343-347.

[4]. Liangyong Chen, YufengDuan, Changsui Zhao, Liguo Yang, Rheological behaviour and wall slip of concentrated coal water slurry in pipe flows, Chemical Engineering and Processing 48 (2009) 12411248.

[5]. Skolnik EG., Schefee RS., Suitability of coals for CWM, Fifth International Workshop on Coal-Liquid Fuels Technoology, Halifax, Nova Scotia, Canada; October 1985; 14-18: p. 265-ology, Halifax, Nova Scotia, Canada; October 1985; 14-18: p. 265-76.

[6]. Zhaobing, G., Feng, R., Zheng, Y., Fu X., Improvement in properties of coal water slurry by combined use of new additive and ultrasonic irradiation, UltrasonicsSonochemistry 2007;14:583-588.

[7]. Li, Y.X., Li, B.Q., Study on the ultrasonic irradiation of coal water slurry, Fuel 2000; 79: 235-241.

[8]. Weidong Li, Weifeng Li, Haifeng Liu, Effects of sewage sludge on rheological characteristics of coal-water slurry, Fuel 89 (2010) 2505-2510.

[9]. Meikap, B.C., Purohit, N.K., Mahadevan, V.J., Effect of microwave pretreatment of coal for improvement rheological characteristics of coal-water slurries, Journal of Colloid and Interface Science 2005; 281: 225-235. 